\title{
Experiential Learning in Vehicle Dynamics Education via Motion Simulation and Interactive Gaming
}

\author{
Kevin Hulme, ${ }^{1}$ Edward Kasprzak, ${ }^{2}$ Ken English, ${ }^{1}$ Deborah Moore-Russo, ${ }^{3}$ \\ and Kemper Lewis ${ }^{4}$ \\ ${ }^{1}$ NY State Center for Engineering, Design and Industrial Innovation, University at Buffalo-SUNY, Buffalo, NY 14260, USA \\ ${ }^{2}$ Milliken Research Associates, Buffalo, NY 14260, USA \\ ${ }^{3}$ Graduate School of Education, University at Buffalo-SUNY, Buffalo, NY 14260, USA \\ ${ }^{4}$ Department of Mechanical and Aerospace Engineering, University at Buffalo-SUNY, Buffalo, NY 14260, USA
}

Correspondence should be addressed to Kemper Lewis, kelewis@buffalo.edu

Received 27 September 2008; Accepted 15 February 2009

Recommended by Xiaopeng Zhang

\begin{abstract}
Creating active, student-centered learning situations in postsecondary education is an ongoing challenge for engineering educators. Contemporary students familiar with visually engaging and fast-paced games can find traditional classroom methods of lecture and guided laboratory experiments limiting. This paper presents a methodology that incorporates driving simulation, motion simulation, and educational practices into an engaging, gaming-inspired simulation framework for a vehicle dynamics curriculum. The approach is designed to promote active student participation in authentic engineering experiences that enhance learning about road vehicle dynamics. The paper presents the student use of physical simulation and large-scale visualization to discover the impact that design decisions have on vehicle design using a gaming interface. The approach is evaluated using two experiments incorporated into a sequence of two upper level mechanical engineering courses.
\end{abstract}

Copyright (c) 2009 Kevin Hulme et al. This is an open access article distributed under the Creative Commons Attribution License, which permits unrestricted use, distribution, and reproduction in any medium, provided the original work is properly cited.

\section{Introduction}

The field of vehicle dynamics has the advantage that every student has either driven or been a passenger in an automobile. For most students, traveling in an automobile has been a regular occurrence for their entire lives. Thus, vehicle motions are inherently familiar to the student. Also, with 30 million vehicles being manufactured each year worldwide, advances in computing technology and electromechanical systems have expanded the influence engineers have over the stability and control of vehicle dynamics. In the field of automotive engineering, while a well-designed passive vehicle is still necessary, augmenting systems such as antilock brakes, electronic skid prevention, yaw control, active differentials, and similar systems improve safety and performance over passive designs. This increased control over the automobile will soon be inseparable from the increased complexity of the subsystems, all of which will combine to determine handling characteristics of the automobile. As a result, engineers are increasingly turning to simulation and virtual prototyping, rather than physical prototyping, to explore new design concepts. As the usage of simulation increases, the demand for students with hands-on experience in configuring and executing simulation-based research will also increase.

The most authentic experience in vehicle dynamics education would be to have students drive real automobiles, perform specific driving maneuvers, use on-board instrumentation to collect vehicle data and modify the vehicle to see resulting changes in its characteristics. While not impossible, concerns about cost, time, space, safety, and weather constraints make this impractical at most schools. An alternative solution is to make use of a simulated environment. Many students have already experienced controlling a sophisticated driving simulation environment in the form of a driving game like Gran Turismo 4 [1] or Race Pro [2], but do not associate the gaming environment with the models and equations that engineers use in designing a vehicle.

This paper presents the development and evaluation of a learning environment that provides a game-based context for vehicle dynamics education. While driving game-based 
approaches have been developed for mental health, driver workload, and rehabilitation applications, gaming-based contexts have not been used in vehicle dynamics education. The presented work describes an innovative methodology for coupling gaming, motion simulation, and educational practices together in a cohesive pedagogical approach.

The project's theoretical underpinnings are based on situated learning where new educational material is presented in an authentic context, and social interaction and collaboration are required for learning to occur. Through a learner-centered approach, students use a physical simulation and large-scale visualization in a gaming-inspired format to discover the impact that design decisions have on a dynamic system.

While incorporating a gaming environment may intuitively make sense from the perspective of creating a more engaging experience for students, not all engaging experiences are educational. A pedagogical basis must first be developed for including a gaming-based learning environment in an engineering course. In Section 2 of the paper, the educational motivation for the work is presented, along with the pedagogy that supports the development of the framework. The development of serious games is presented in Section 3, providing a background for the development of the gaming context for vehicle dynamics education. The learning environment, core methodology, and accompanying gaming infrastructure are detailed in Section 4. Section 5 presents the incorporation of the simulation game environment into two upper-level mechanical engineering courses, including assessments about the impact of the experience on the students. The paper is concluded with a set of collective insights and conclusions.

\section{Experiential Learning}

Relating theoretical and analytical results to real-world phenomena is one of the most difficult tasks in education. While text, equations, diagrams, and graphs are an efficient means of presenting large amounts of information, such representations are necessarily abstractions of reality. A significant part of a student's learning process is learning how to transform these abstractions into knowledge that will allow them to applying their understanding to real-world products and systems. Many attempts to cross this gap are used by educators, including in-class demonstrations, laboratory experiments, videos, and computer graphic simulations [36]. In a study of the application of information technology to education, the President's Information Technology Advisory Council (PITAC) recommended the development of technologies for education and training that use simulation, visualization, and gaming to actively engage students in the learning experience [7]. In the same report, PITAC also recommended the development of educational experiences that provide learners with access to world-class facilities and experiences using either actual or simulated devices.

The serious gaming approach presented in this paper concentrates on developing an innovative means of incorporating items from the accreditation criteria to assist in the development of educational experiences that will translate well to industrial application [8]:

(i) an ability to apply knowledge of mathematics, science, and engineering;

(ii) an ability to design and conduct experiments as well as to analyze and interpret data;

(iii) an ability to identify, formulate, and solve engineering problems;

(iv) an ability to use the techniques, skills, and modern engineering tools necessary for engineering practice.

In addition to the guidance of the accrediting body, the National Survey of Student Engagement (NSEE) provides an opportunity for senior college students to evaluate their educational experience against five benchmarks [9].

(i) Level of Academic Challenge: challenging intellectual and creative work is central to student learning.

(ii) Student-Faculty Interaction: contact with professors offers students an opportunity to see how experts think about and solve practical problems.

(iii) Active and Collaborative Learning: students learn more when intensely involved in the educational process and are encouraged to apply their knowledge in many situations.

(iv) Supportive Campus Environment: students perform better when their college is committed to their success and cultivates positive social relationships among different groups of people.

(v) Enriching Educational Experiences: learning opportunities inside and outside classroom (diversity, technology, collaboration, internships, community service, capstones) enhance learning.

These points of guidance emphasize the need for students to not only study, but also to practice the application of their knowledge in an active manner that is similar to what they will experience after college. One approach to provide these experiences is simulation, which enables practicing engineers to determine the performance of a design before the system is actually constructed. Consequently, an engineer may explore the merits of alternative designs without physically building the system, significantly reducing the cost of designing a product. Many opportunities exist in engineering education to mimic how engineers in industry have increasingly turned to simulation in product and systems design processes.

However, the use of simulation does not ensure student engagement. In order to provide an engaging experience for students to learn in an educational context, the simulation must be developed with student engagement in mind. Different types of simulators can be effective in teaching, training, or demonstrating design concepts to students. Computer graphics-based simulators that display the simulated system provide the user with a meaningful understanding of the system's behavior. Physical simulation tools, such as motion simulators, augment the display of graphical information 
with physical motion, providing learners with immediate feedback when designing dynamic systems and the opportunity to both see and experience the impact of their decisions first hand. Many students are already familiar with computer games that are based on physically accurate physics engines and high-fidelity graphics and have the ability to adjust some parameters of the underlying simulation. In this situation, students may adjust parameters, but not experience any lasting learning. A successful pedagogy will couple authentic experiences for a student along with support from an instructor to promote lasting learning.

While serious gaming could be applied to a number of engineering courses, vehicle dynamics education was identified as an area with high potential for the development of a simulation game-based learning environment. Designers of automotive vehicles often use motion simulation to help overcome difficulties in the development of new vehicle designs. Creating a prototype vehicle is costly and controlling environmental conditions is difficult, if not impossible. One alternative is to simulate the vehicle dynamics through the use of a motion platform. Developing a serious game for vehicle dynamics education would provide learners with an authentic engineering experience in an engaging and relatable manner. The next section provides some background of the evolution of games and their use as educational tools.

\section{Serious Gaming for Education}

Video games and gaming systems have increasingly been found in applications more diverse than just entertainment, including use in training, education, research, and simulation. This emerging field of Serious Games (e.g., [10, 11]) is intended to provide an environment for an accurate and an engaging context within which to motivate participants beyond the capability of conventional approaches.

Though individual researchers may each have different definitions for the term "Serious Games", various widelyaccepted subclassifications of the genre exist. Of particular interest for the research at hand are two such classifications: (a) games-based learning, and (b) simulation games. Prensky [12] develops the classification of Games-Based Learning as "games with defined learning outcomes" and games that "are designed to balance subject matter with game-play, and the ability of the player to retain and apply the subject matter to the real world." Ruohomaki [13] classifies a game that "mixes skill, strategy, and chance to simulate some aspect of reality" as a Simulation Game. The Simulation Game classification has numerous relevant subclasses of its own, including "vehicle simulation" (i.e., providing a participant with a realistic interpretation of operating a vehicle, such as an automobile), and even more specifically, "racing games" (e.g., first- or third-person driving games). The approach presented in this work relies on a simulation game architecture to achieve the educational goals of the course.

Numerous computer games, all of which were developed primarily for entertainment purposes, have had ongoing influence on the driving simulation developments in the

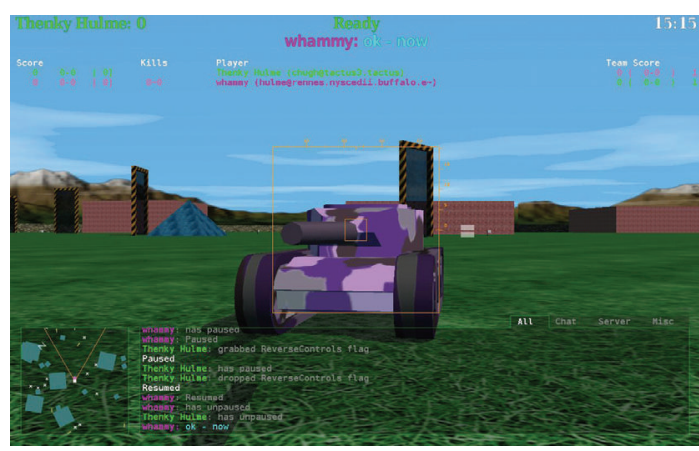

Figure 1: BZflag.

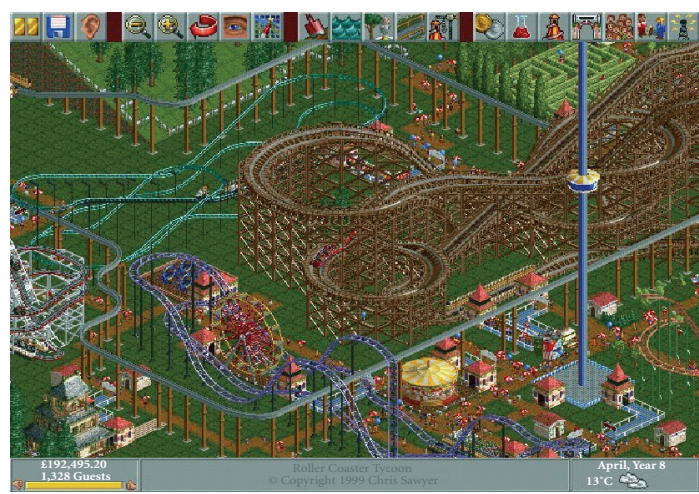

FIgURE 2: Roller coaster tycoon.

present work. For dissemination and realism, it is useful to have a simulation that allows for multiple participants simultaneously [14]. It is also likely that these participants may not be colocated (i.e., in the same room, the same city, the same state, or even in the same country). Thus, an overthe-network capability is certainly desirable. An effective example in the gaming world that addresses this need is the game called BZflag [15], originally designed in 1992. BZflag, shown in Figure 1, is a simple networked 3D multiplayer game, in which the objective is to destroy your opponent's tank. BZflag was modeled after a 1980 Atari tank combat game called Battlezone [16]. Battlezone is a game many consider to be the very first serious game, as a version of it was used for baseline Military ground vehicle training [17].

Various gaming systems exist that allow the player to generate a developer-defined environment within which to interact. One example is SimCity [18], first released in 1989. The objective of the game, quite simply, is to design and build a virtual city. The developer is presented with an empty plot of land, within which buildings, roadways, landscaping, and so forth. can be placed to form a representation of a functional city. The popularity of the game was due, in large part, to its open-endedness, reusability, and ease-of-use. These types of "Sim" games have become immensely popular in recent years and have led to various similar games that have ties to moving vehicles and transportation and can be "driven" from a first-person perspective. 


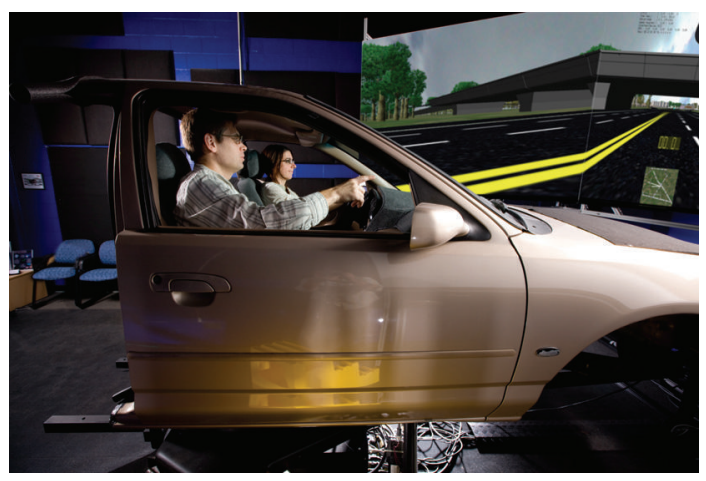

Figure 3: Moog 2000E motion platform and passenger cabin.

Easily the most popular of these newer breed of games is Roller Coaster Tycoon [19], first released in 1999 and shown in Figure 2. Similar to SimCity in that the player is presented with an empty plot of land, the objective is to build a functioning amusement park, including pathways, landscaping, and of course rides. During game play, the player builds a virtual roller coaster piece-by-piece using track segments and then rides the finished product. The simulator includes a simplified real-time physics engine, so the roller coaster ride behaves true to real-world form. While these examples provide a small sample of the game-based learning applications that have been implemented, they provide a sufficient model for the creation of a simulation game to enhance learning about a specific topic. The next section provides a description of the simulation game and the physical environment where the students play the game.

\section{Driving Simulator Game for Experiential Learning}

This section describes the methodology behind the implementation of a motion-based simulation game in the form of a driving simulator geared toward undergraduate and graduate engineering students. This simulation game was generated primarily for education, research, and training, and for sake of authenticity and it exploits the availability of an on-site motion simulator. A brief background on motion simulators is presented first.

4.1. Motion Simulators. A motion platform, parallel manipulator [20], or Stewart Platform [21, 22], is a powered, mechanical, self-contained system for the execution of motion-based simulation and is described by the number of degrees-of-freedom (DOF) that can be simulated by the hardware. Figure 3 shows the motion platform currently in use in NYSCEDII's simulator facility. The motion platform has an on-board computer that converts incoming messages into actuator commands that result in the movement of the top of the platform. Such systems are commonly used in the automotive and other industries (e.g., flight, training, and entertainment). NYSCEDII's passenger cabin located atop the platform is a 1999 Ford Contour, cut in half to accommodate a front seat driver and passenger.

One of the primary advantages of motion simulators is that they are able to provide users with immediate feedback when designing dynamic systems. When a student drives or rides in the simulator, they experience many of the same sensory inputs as in a real vehicle.

4.2. Methodology. A common complaint of graduating undergraduate engineers is that while they are well versed in engineering theory, they are under rehearsed in engineering application. Many engineering curricula do not spend enough time assuring that when students complete their studies that they enter the work force with sufficient practical, experiential, and hands-on knowledge of their craft. To this end, PITAC [7] has indeed recommended the development of "technologies for education and training that use simulation, visualization, and gaming" and "educational experiences that provide learners with access to world-class facilities and experiences using either actual or simulated devices."

One option for exposing engineering students to handson driving experiences would be to use an actual vehicle upon an actual roadway or test track. While this is undoubtedly the most authentic means of exposing a student to the practical principals of real world driving, clearly there are insurmountable safety concerns that deem this option impractical. As well, the adaptation of existing high-fidelity driving games (e.g., Gran Turismo [1]) might seem to be a more straightforward option than the full development of a complete games-based driving simulation. However, such off-the-shelf games, geared primarily for an entertainment audience, do not allow for the creation of custom learning scenarios that are designed to focus a student's attention on the system dynamics rather than the outcome of a particular race. By developing an engaging simulation game that focuses on the differences between varying simulation models (e.g., vehicle model fidelities, vehicle types, tire dynamics, etc.), students can develop a better understanding of the information available as engineers make decisions at different stages of a vehicle design project. Data-logging can be performed directly within the simulation, changes to the vehicle can be made very quickly-even while driving, and weather and climate conditions are operator controlled.

At its core, the experiments developed can be classified as a serious game as they integrate gaming elements, simulation elements, and pedagogical elements by including support from system infrastructure, instructors, and peers [23]. They balance subject matter with game-play, focusing on the skills and strategies of the driver to retain and apply the subject matter to the real world. Much of the novelty in the simulator is its integration of computer programming, computer graphics, linear algebra, numerical methods, and systems analysis with the vehicle dynamics theory fundamental to the Road Vehicle Dynamics (RVD) courses for which the simulation was developed. 
The methodology employed, adapted from the general structured process for education gaming and simulation [24], is as follows.

(1) Define learning outcomes.

(2) Select a set of simulation activities or gaming tasks to support this required learning outcome with an appropriate form of assessment.

(3) Consider a strategic ordering of the game tasks within the gaming session and assessment process.

(4) Implement the session with proper consideration given to preparation, execution, and reflection.

(5) Assess the impact and effectiveness of the session.

(6) Redesign the session according to feedback given.

The specific implementation of this methodology is described in Sections 5 and 6. The underlying hardware and software framework of the game-based vehicle simulation environment is described in the next section.

4.3. Framework. The simulation game has been implemented using the $\mathrm{C}++$ programming language [25] and constructed on the Windows platform within Microsoft Visual Studio. The entire gaming framework is outlined in the following steps; refer to Figure 4 for a flowchart overview.

4.3.1. Establish Network Connection with Motion Platform (MP) (Process a). The computer integrated into the MP can send/receive motion commands, in the form of datagrams [26], from another computer on the network. Figure 5 presents a screen capture of Moog's Base Maintenance Software [27], for monitoring the state of the six actuators on the motion platform (e.g., error messages, status messages, etc.) in real-time as the simulation executes. This software runs on the On-Board Computer (OBC) and is displayed on an off-board monitor.

4.3.2. User Controls Simulation with Human Interface Device (HID) (Process b). The driver controls the simulation while on-board the MP by way of a USB steering wheel and pedals. Commands are captured using DirectX's DirectInput Application Programmer's Interface (API) $[28,29]$ in real-time. The selected gaming device, shown in Figure 6, contains numerous components that must be continually tracked, including the accelerator, brake, clutch pedals, the singleaxis motion of the steering wheel, the paddle shifters, and 6 buttons located on the steering wheel.

4.3.3. Simulation Computer (SC) Receives Inputs, Performs Analysis for Current Time Step (Process c). The states of the vehicle dynamics model (described in Section 5) are now computed at 60 Hertz and must be converted into DOF's (i.e., roll, pitch, yaw, heave, surge, and sway)—see Figure 7. This conversion typically involves scaling, limiting, and tilt coordination [30], collectively known as washout filtering [31]. The work presented here uses a proprietary filter based upon a classical washout algorithm [32].
4.3.4. Updated State Delivered to Projection System (PS) and Visualization Screens (VSs) (Process d). The scene graphics are now updated and sent to the PS and to the three $48 \mathrm{ft}^{2}$ VSs. The simulation graphics have been developed using OpenGL [33], selected primarily to demonstrate that a useful game-based learning environment can be created without the optimizations of a scene graph toolkit (e.g., OpenSceneGraph [34] and Delta3D [35]). The virtual world is populated with a sky, ground (grass, pavement), the driven vehicle and adjacent vehicles, track/roadway obstacles (e.g. cones), curbs, walls, trees, roadway signs, the vehicle control panel, and various other details to promote an authentic representation of a test track. Figure 8 presents screen captures of various simulations.

4.3.5. DOF's Sent to Motion Platform Interface Computer (MPIC) (Process e). The updated DOF's are delivered by the SC to the MPIC, dedicated to the motion process and requires an uninterrupted $60 \mathrm{~Hz}$ flow of data. This is accomplished using Parallel Virtual Machine (PVM) [36], a networking API based upon TCP/IP Socket programming [37] and coded in ANSI C. PVM allows us to easily and reliably send data packets between computers and handles cross-platform, nonheterogeneity issues transparently (e.g., endian/byte-order concerns, char-to-float data conversion, etc.). Once the MPIC receives the updated DOF's, these commands are finally delivered directly to the MP for motion processing.

4.3.6. MPIC Delivers Computed DOF's to MP (Process $f$ ). An "instance" of the MP is declared and assigned an IP address. The instance is initialized, and then motion commands are updated and delivered to the MP at a rate of precisely $60 \mathrm{~Hz}$. When the simulation is complete, the MP instance is then shutdown, thereby completing the motion process.

4.3.7. Audio States Delivered to Mixer/Amplifier (MA) and 2.1 Sound System (SS) (Process g). The simulation game uses OpenAL [38] for adding sound events synchronized with the graphical simulation. Sound is a vital simulation cue, and it enhances the impact of visualization and motion cues. Examples include vehicle ignition, engine idle, squealing tires, cone strikes, spinout/crash, police siren, and vehicle shutdown. Each cue can be made to vary in pitch/gain in accordance with the present state of the simulation. The audio states are sent to the mixing board, are processed, and then are delivered to the amplifier, which delivers the audio signal to a 2.1 stereo sound system, comprised of front-left (SS-L), front-right (SS-R), and subwoofer (SS-SW) channels.

4.3.8. Emergency Stop Switch Is Available, at All Times, to Terminate the Simulation (Process $h$ ). Throughout the simulation, both the simulation driver (on board) and simulation operator (off board) can activate an Emergency Stop switch (to view the on-board switch, refer to bottomright corner of Figure 6). When the red button is struck, the motion simulation comes to an immediate, premature, and smooth conclusion. Such a safety device is required in 


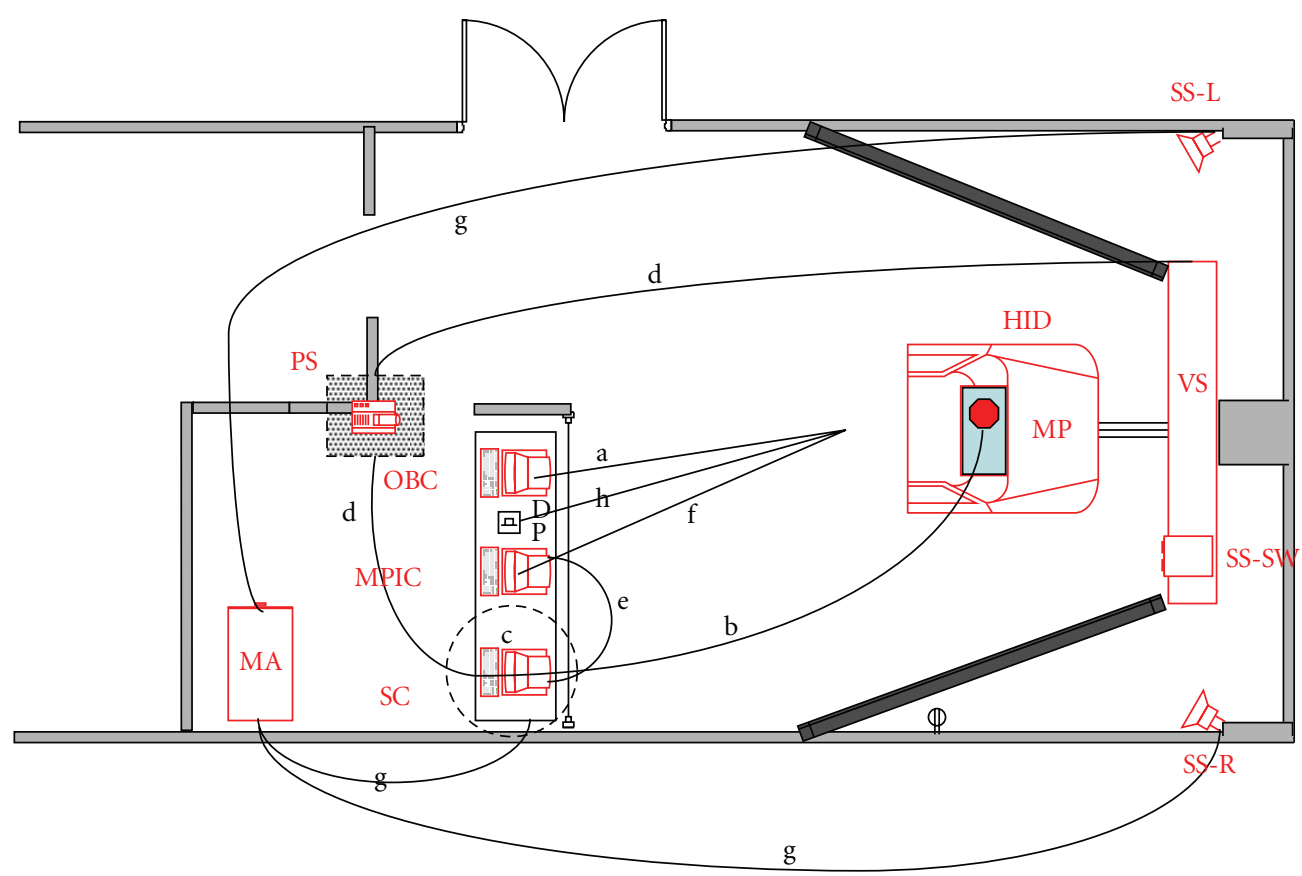

FIGURE 4: Driving simulation game-process flowchart.

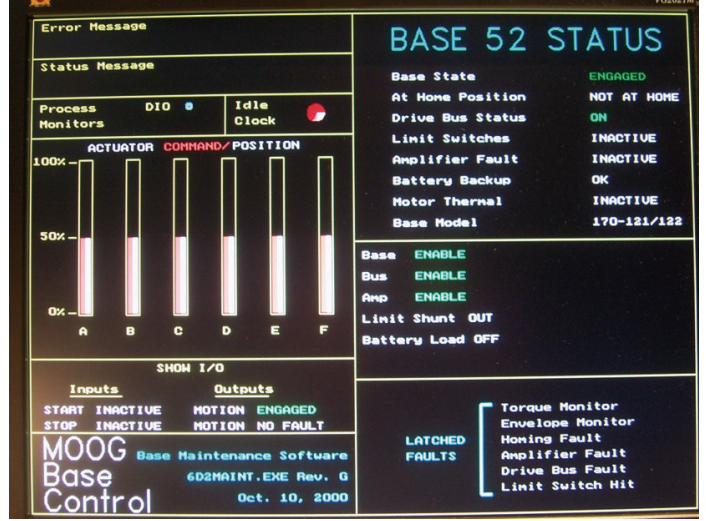

FIgURE 5: OBC display screen.

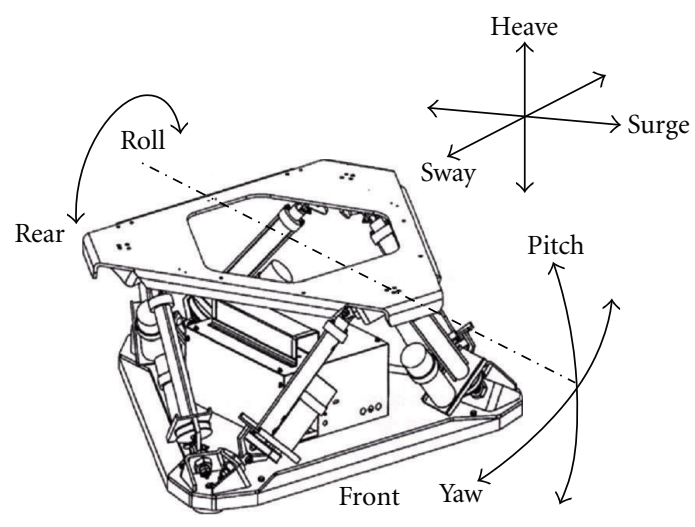

Figure 7: Motion platform DOF's.

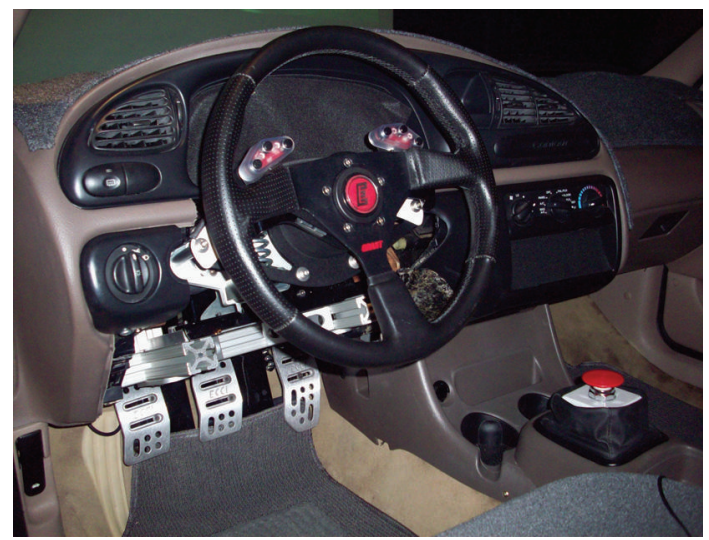

Figure 6: On-board HID. the case of a hardware malfunction or in the event of driver panic/illness, or any other circumstance that might deem premature termination of the present simulation.

The next section discusses the incorporation of the simulation game described into a Road Vehicle Dynamics (RVD) engineering course curriculum, using an experiential learning context.

\section{Gaming Implementation}

The simulation game is incorporated into a two-course sequence of technical electives on automobile vehicle dynamics, Road Vehicle Dynamics 1 and 2 (RVD1 and RVD2). These courses are open to senior undergraduate and graduate students. Between 60 and 75 students typically enroll in RVD1, with over two-thirds continuing in RVD2. 


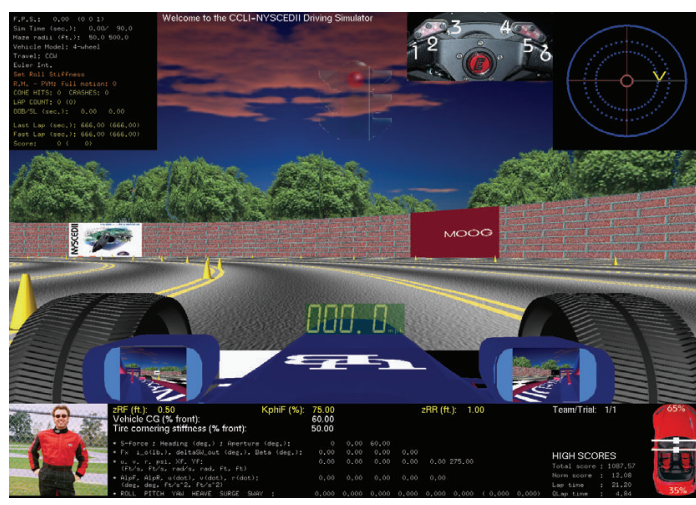

(a)

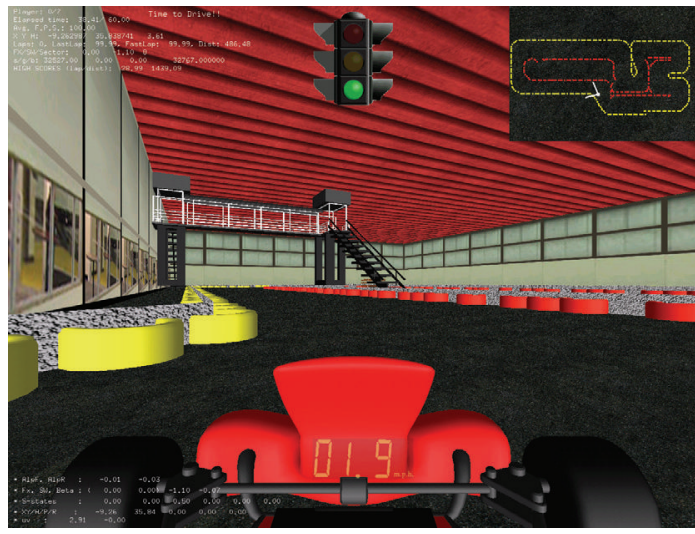

(c)

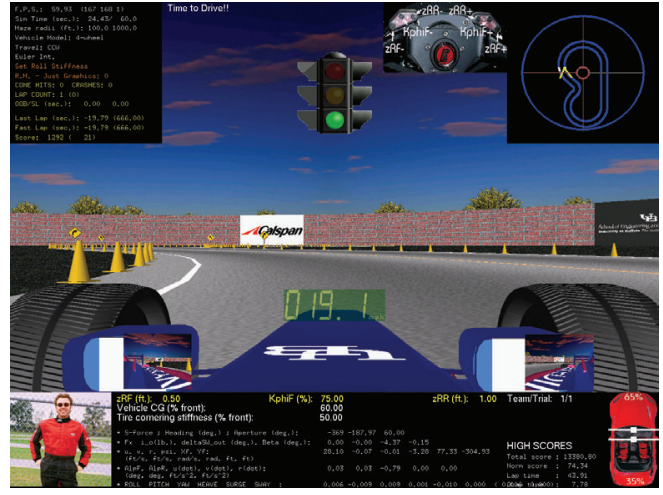

(b)

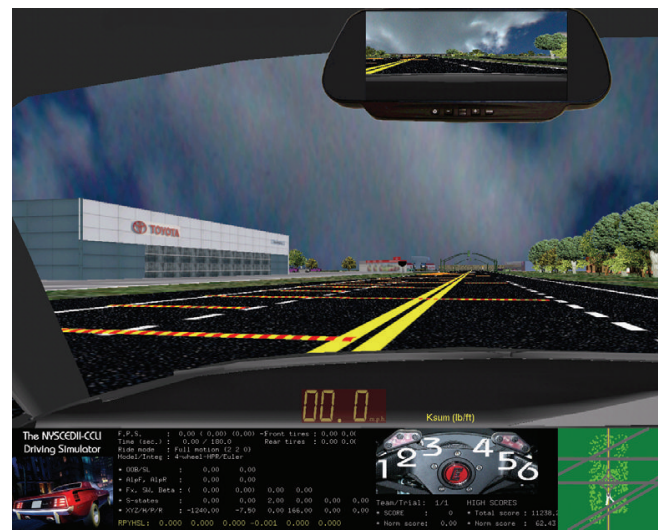

(d)

Figure 8: (Clockwise, from (a) Experiment 1 ("Skid Pad"), (b) Experiment 2 (“Tri-Radii”), (c) Future Work ("Networked Karting”), and (d) Experiment 3 ("Millersport Hwy").

RVD1 is an introductory course on the basics of automobile motion, stability, and control. This includes a review of tire performance and modeling, exploration of the elementary Bicycle Model of vehicle dynamics, and the development of a more detailed four wheel model [39]. A secondary goal of the course is to apply engineering skills and techniques learned in the first three years of the mechanical engineering curriculum to a specific field, in this case the field of vehicle dynamics. The broad nature of the material naturally lends itself to such a review, reinforcing the value of the engineering curriculum, giving students the satisfaction of being able to apply their engineering skills to a particular topic and mimics the process of merging these foundational abilities with details of a specific knowledge area as will be required when entering the workforce. The course traditionally has consisted of daily lectures, weekly homework assignments, and three exams.

RVD2 builds on RVD1, exploring advanced techniques such as quasistatic vehicle analysis. Oscillations of the sprung and unsprung masses are investigated with a focus on ride comfort, and the design and analysis of suspensions are covered. The course has more open-ended material and higher expectations of independent student learning, with several paper reviews, in-class presentations and projects throughout the semester.
5.1. Experiment 1: Low-Fidelity Simulation, Introductory Gaming Scenario in RVD1. The first experiment is presented in the context of the overall methodology, as presented in Section 4.2

Define Learning Outcomes. The learning objective of the first experiment is for students to discover through experiential gaming the fundamental effects that tire properties and vehicle center of gravity location have on vehicle stability, control, and overall performance. Prior to the exercise, students complete the first five weeks of the course focusing mostly on tire behavior and modeling, including a basic introduction to a standard dynamic model of the automobile, although this is limited to the structure of the model with no discussion of its behavior.

Simulation Activities. The simulation model used in the first experiment is the classic Bicycle Model of the automobile [39]. This model makes many simplifying assumptions that allow it to be easily analyzed and understood, while still providing all the fundamental characteristics of a real vehicle. The key elements of the Bicycle Model are as follows. It has three degrees-of-freedom (forward velocity, lateral velocity, and yaw rate), plus those used to track the motion of the 
vehicle in the world (forward position, lateral position, and heading angle). Both front tires are treated as a single tire, as are both rear tires, thus the Bicycle Model name. Figure 9 shows a top view of the Bicycle Model representation. The tires are represented as bilinear, as illustrated in Figure 10, described by (i) a cornering stiffness slope at low slip angles, and (ii) as a constant lateral force output above a certain "breakaway" slip angle.

Driver inputs from the on-board steering wheel and pedals are used as inputs to the Bicycle Model which generates updated model states as outputs through numerical integration during every time step. One environment in the simulation game replicates a proving ground skidpad, which is a circular course (of outer radius 500 feet), with street lines indicating several internal lanes of varying radii. A significant amount of vehicle testing and tuning has been performed at skidpad facilities [40-42]. This experiment performed for this research effort involves one of the fundamental tests-driving at ever-increasing speed while attempting to maintain a given radius.

\section{Task Ordering:}

Tasks 1 and 2. In the first two driving tasks, the driver is given a vehicle with equal strength (i.e., identical cornering stiffness and breakaway slip angle) tires on the front and rear. The first task places the center of gravity (CG) ahead of the vehicle midpoint, while the second task places it behind the vehicle midpoint. The student drives around the skidpad at slowly increasing speed, up to (and beyond) the tire saturation points. Students are asked to describe how the vehicle felt, how stable it was, and how their steering input changed as speed increased. They are also asked to describe what happened when a tire (front or rear) saturated. These tasks expose the students to vehicles with different understeer gradients, stability indices, yaw rate responses, and limit behaviors.

In Task 1, the CG is ahead of the vehicle midpoint, resulting in a vehicle with static and dynamic stability. In short, the vehicle does not spin out while cornering. As vehicle speed increases, the amount of steering required to stay on the constant radius circle also increases, indicative of an understeer vehicle. This is also consistent with passenger car behavior (i.e., passenger cars are designed to have understeer). Task 1 saturates the front tires first, forcing the driver to slow down in order to tighten the turn.

In Task 2, the CG is behind the vehicle midpoint, resulting in a vehicle with static instability but with dynamic stability up to a certain speed. Beyond a certain speed the vehicle becomes unstable and spins out. Unlike the understeer car of Task 1, this oversteer car requires less and less steering to stay on the circle as speed increases. Task 2 saturates the rear tires first, resulting in a spin-out.

Tasks 1 and 2 allowed the driver to become familiar with the motion simulator and experience the behavior of two very different vehicles. Task 3 built upon these experiences.

Task 3. In the third task the driver is given a vehicle with the CG at the vehicle midpoint and chooses tires that have the cornering stiffness distribution biased to either the front or the rear. Based on that decision, the driver is asked to predict if the car will feel like the one driven in either the first or the second task. This prediction is not confirmed by the instructor before the trial run, but instead the student is asked to indicate as soon as possible while driving which of the previous cars it felt like.

This task enables students to develop hypotheses about the relative location of the CG and the cornering stiffness distribution, test the hypothesis, and draw conclusions. In short, if the CG is forward of the cornering stiffness distribution the vehicle has understeer, is stable, and behaves similarly to the vehicle in Task 1 . When the CG is aft of the cornering stiffness distribution the vehicle has oversteer, is unstable above a certain speed, and behaves similarly to the vehicle in Task 2.

Task 4. The fourth task challenged the driver to optimize the CG location while driving to achieve the fastest possible speed around the skidpad. Students used two buttons on the steering wheel to move the center of gravity and felt the stability and response of the vehicle change as they moved the CG. The cornering stiffness distribution is unknown to the students in this case. This task allows students to further develop and test their hypotheses about the relationship between vehicle parameters.

Session Implementation. A total of 73 students participated in the experiments, separated into 11 groups. Each group spent an hour with the motion simulation system performing the four specific driving tasks. At the end of the experiment each group received a copy of the data collected during all the runs for their analysis.

Assessment. The assessment phase focused on both how well the students learned the key concepts in each experiment, but how their gaming experiences impacted their education and learning opportunities.

Learning Objectives. In Tasks 1 and 2, students were asked while driving if they were steering more or less as speed increased, and all were able to notice the trends. Students noted in Task 2 how much more concentration and steering corrections it took to keep this vehicle on the circle. Students also noted how the vehicle cornered more "tail out" than the Task 1 vehicle-this is an observation that would have been difficult to make without the motion cues on the motion platform or without the use of a real vehicle.

After the experiment, students analyzed their results, including a plot of steering wheel angle versus lateral acceleration. A sample of one of the student plots is shown in Figure 11 for the Task 1 vehicle. The slope of this curve is the understeer gradient, and the intercept is the Ackermann steer angle [42]. These values are shown by the linear fit to the recorded data. The "noise" in the data is a result of the student correcting the vehicle path by steering while increasing speed-its very difficult to trace a circle precisely 


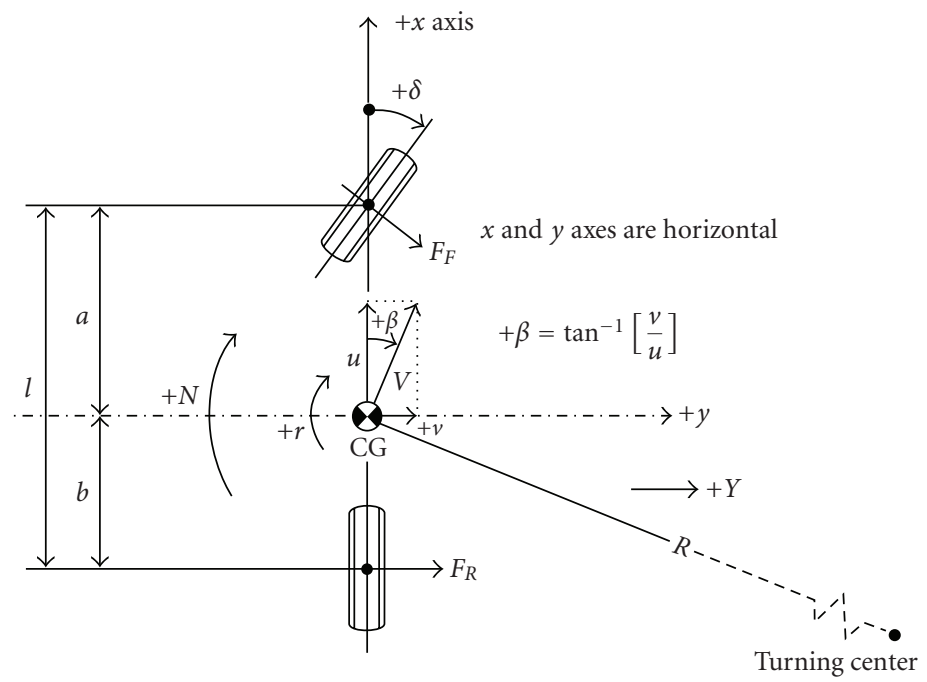

Figure 9: The bicycle model of the automobile.

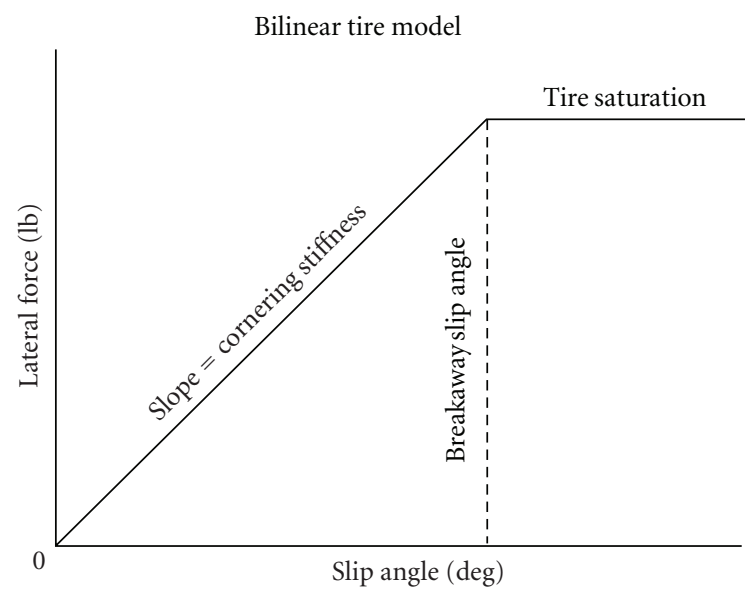

FIgure 10: The bilinear tire model, shown for turning in one direction.

when speed is varying. The excursion in the right end of the data is attributed to the start of the run when the vehicle first starts moving. The excursion at the left end of the data shows what happens when the front tires saturate.

A similar plot was produced for the Task 2 vehicle, as shown in Figure 12. Here, the slope of the steering angle versus lateral acceleration curve is negative, indicating an oversteer vehicle. Oversteer vehicles are dynamically stable up to a certain critical speed due to yaw damping, above which they want to spin out. By the time the vehicle is cornering over $-25 \mathrm{ft} / \mathrm{sec}^{2}$ the amount of steering required to stay on the circle is nearly zero. At the far left of the diagram the steering trace shoots upward sharply-this is a result of the driver trying to catch the vehicle as it spins out.

In Task 3, when the students were asked to announce as soon as possible which vehicle (Task 1 or Task 2) the car felt like, they were not able to do so at low speeds. It was not until speeds increased above approximately $35 \mathrm{mph}$

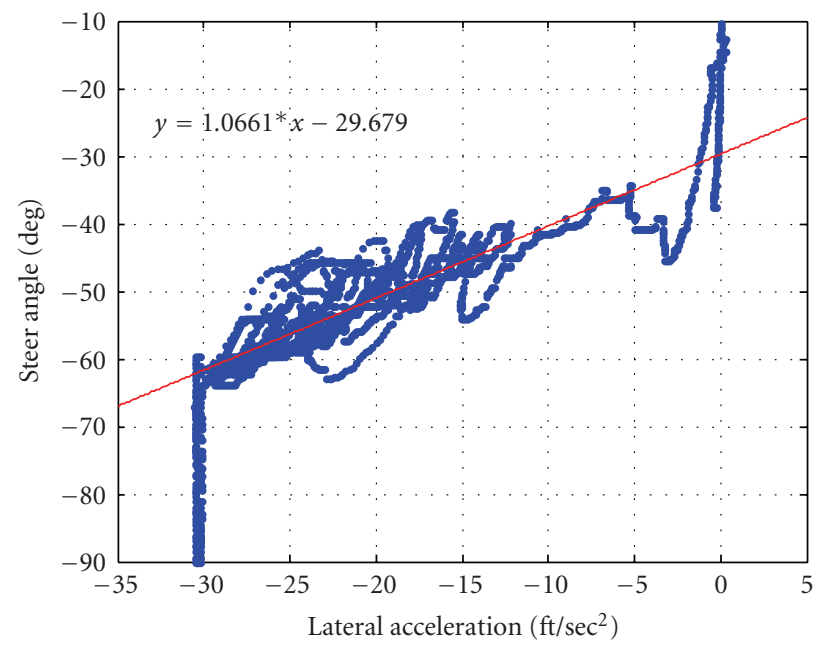

FIgUre 11: Student data for a Task 1 vehicle showing the understeer gradient.

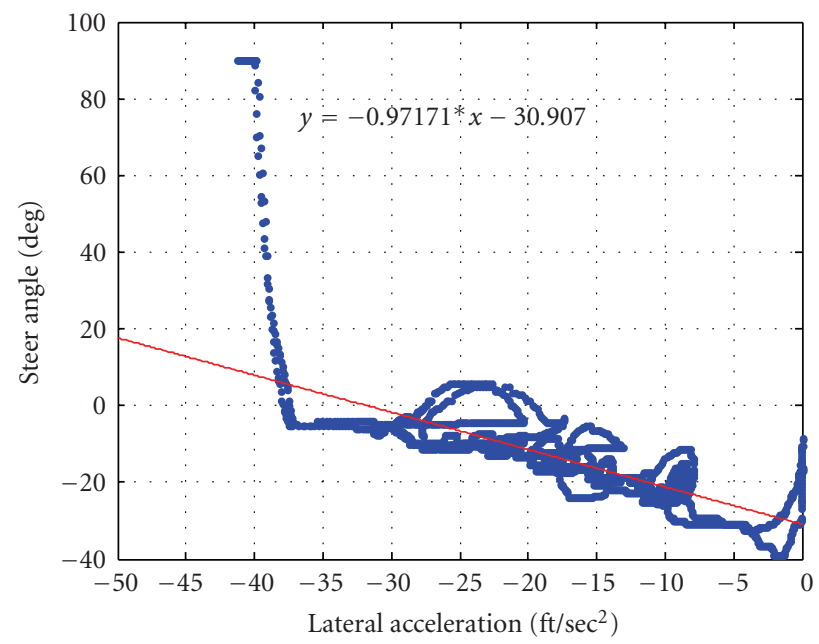

FIGURE 12: Student data for the Task 2 vehicle. 
TABLE 1: Pre- and posttest open responses.

\begin{tabular}{|c|c|c|}
\hline How could engineering education be improved? & $\begin{array}{c}\text { Pretest } \\
66 \text { students responded* }\end{array}$ & $\begin{array}{c}\text { Posttest } \\
60 \text { students responded } *\end{array}$ \\
\hline (1) More hands-on experiences & $17(26 \%)$ & $18(30 \%)$ \\
\hline (2) More practical/authentic/realistic experiences & $13(20 \%)$ & $8(13 \%)$ \\
\hline $\begin{array}{l}\text { (3) More experience with what is done in industry including the } \\
\text { technology and equipment currently used in industry }\end{array}$ & $10(15 \%)$ & $4(7 \%)$ \\
\hline (4) Required internships/more internships & $7(11 \%)$ & $11(18 \%)$ \\
\hline (5) More group/interactive experiences & $4(6 \%)$ & $2(3 \%)$ \\
\hline (6) More electives offered earlier & $2(3 \%)$ & $7(12 \%)$ \\
\hline (7) More tours of/field trips to engineering companies and facilities & $1(2 \%)$ & $3(5 \%)$ \\
\hline
\end{tabular}

* Note that some students wrote multipart responses that were classified in more than one category.

that students could definitely tell the difference. There are two reasons for this. First is the overwhelming presence of stabilizing yaw damping at low speeds. Since both cars were very stable at low speeds their response felt similar. It was not until speed increased and yaw damping diminished that the differences in behavior were easily detected, at which point they were obvious. Second, at low speed it is difficult to accurately trace a large radius circle. Thus, it was difficult for students to tell if the steering angle required was increasing or decreasing with speed when speeds were low. These kinds of experiential-based insights would have been impossible without the gaming experiment.

In Task 4 , by the end of the experiment, every group was able to empirically place the CG within $1-2 \%$ of the theoretical optimum. Students were asked what strategy they were going to use to find the optimum as the experiment proceeded. By the second and third drivers, the students realized that they needed to approach the optimum from the stable side (i.e., CG too far forward) to avoid spin-outs. They would note the CG location when a spin-out did occur, and they made sure to keep the CG ahead of that point during further adjustments.

Impact on Education. A survey was administered to the students in the RVD1 class at the beginning (pretest) and then again at the end (posttest) of the semester. The survey contained the open-ended question. How could engineering education be improved? An outside evaluator read and coded the student responses placing them in the categories shown in Table 1. Student responses commonly fell into categories that suggested the need for the environment that the RVD1 class was trying to provide as shown in Table 1. While it would be speculation, it is interesting to note how the number of responses in items 2 and 3 dropped. Was that due in part to the experiences the students had in the RVD1 course? Similarly, it is interesting to note how the number of responses to item 6 increased. Again, was that due in part to the students' perceived value of RVD1, an elective course? Further investigation is needed to answer these questions. Also, specific comments to the question, when posed at the end of the semester, seem to highlight the benefit of the incorporation of the simulation game into RVD1.
It is also worthy to note that 43 of the 73 people (59\%) enrolled in the Road Vehicle Dynamics 1 course in the fall 2007 semester enrolled in the Road Vehicle Dynamics 2 course (which contained the advanced gaming module). Considering that both are elective courses in degree programs that allow for just 2-3 electives speaks to the student response to the courses. In addition, a number of the 30 students who did not enroll in the sequel class were graduating seniors and therefore were not eligible to enroll in the course.

Experiment Redesign. Based on the feedback of the participants, instructors, and technical support personnel, a new set of experiments were designed for the following course, Road Vehicle Dynamics 2. This included more advanced simulation models, gaming environments, and instructional tasks.

5.2. Experiment 2: High-Fidelity Simulation, Advanced Gaming Setting. The second experiment is also presented in the context of the overall methodology, as presented in Section 4.2 .

Define Learning Outcomes. The learning objective of the second experiment is for students to discover through both their first hand experience and a postprocessing of the data they generated, the fundamental dynamics and impact of the roll stiffness distribution, roll center heights, friction ellipse effects, weight transfer, and the dropped-throttle oversteer. In addition, a secondary objective is for students to understand g-g diagrams and moment method ( $\mathrm{CN}-\mathrm{AY}$ ) diagrams using the data generated during the experiment.

Simulation Activities. There were two major additions to the vehicle model for Experiment 2. The first is a new tire model. Unlike the linear tire model of Experiment 1, Experiment 2 uses a nonlinear and load sensitive tire model. This model was based on tire data collected at the Calspan Tire Research Facility [43] for the FSAE Tire Test Consortium [44] and subsequently modified to suit the specific vehicle application. It is in the form of a Nondimensional Tire Model [42] and 
represents tire lateral force as a function of vehicle slip angle and normal load.

The second addition involved the transition from a Bicycle Model to a full four-wheel vehicle model with lateral and longitudinal load transfer based on vehicle lateral and longitudinal accelerations. This calculates wheel loads at any given vehicle operating condition so that the loadsensitive tire model can be utilized. A simplified suspension, represented by a roll stiffness distribution and front/rear roll center heights [42], allows additional ways to change vehicle handling characteristics over Experiment 1. While the resulting model is still very simple compared to comprehensive vehicle simulations, it is the next step towards such models and makes for a very useful educational too.

\section{Task Ordering:}

Task 1. In the first task, the student revisits the skidpad of Experiment 1 (Section 5.1). Each student drives a baseline vehicle at ever increasing speeds up to the limit, all the while being conscious of how much steering is required to stay on the circular skidpad. Then, one of the parameters (roll stiffness distribution, front roll center height, or rear roll center height) is set to a new value and the student is asked to describe the effect of this change. Task 1 also introduced students to the ability to change the values of the vehicle parameters while driving. The steering wheel contained three thumb-activated buttons on each side of the wheel, one each for roll stiffness distribution, front roll center height, and rear roll center height. Once the student had completed the understeer gradient part of the task, he/she was asked to adjust the parameter to experience its effects on vehicle handling, and then to determine an optimum parameter to achieve the highest speed on the skidpad.

Tasks 2 and 3. Tasks 2 and 3 presented a new driving world to the students, named the "Tri-Radial Speedway". The name arises from the design of the racetrack in the simulationthree corners each with a different radius plus one long straightaway (layout of the track is shown in Figure 13). In Task 2, the students were given a baseline car and told to drive around the track as fast as possible, which achieved two purposes. First, it allowed students to learn the track and identify reference points for braking, turning, and so on. Secondly, it acclimated drivers with the vehicle performance. Driving at the limit on a skidpad is different from driving at the limit on a racecourse in that on the skidpad the vehicle is always at approximately constant speed. On the racetrack the vehicle speed is changing. Under braking there is load transfer to the front of the vehicle which is destabilizing and could result in a more uncontrollable vehicle.

In Task 3, students were asked to vary one of the three vehicle parameters while driving to achieve a better lap time than they could with the baseline vehicle. Here students had to consider the tradeoffs in setting-up a vehicle. How much steady-state cornering do you sacrifice for good turnin stability? Are the settings that feel good to the driver identical to the theoretical optimum with a perfect driver?

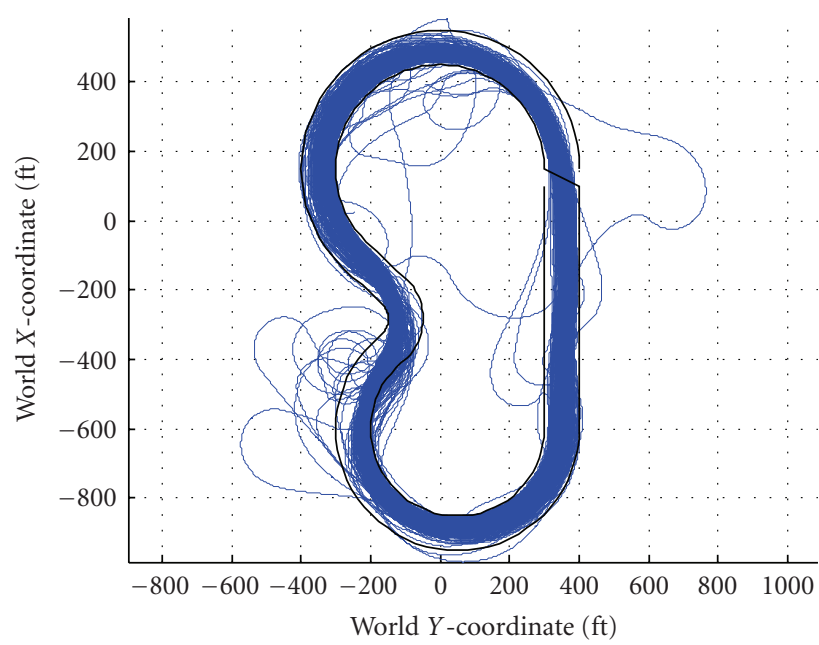

Figure 13: Student vehicle paths plotted on the Tri-Radial speedway.

The answer is "no", and a compromise needs to be reached. How much of a compromise depends on how smooth the driver is.

Session Implementation. A total of 41 students participated in the experiments, separated into 8 groups. Each group spent an hour with the motion simulation system performing the three specific driving tasks. At the end of the experiment each group received a copy of the data collected during all the runs for their analysis.

Assessment. The assessment phase for this experiment also focused both on how well the students learned the key concepts in each experiment, and how their gaming experiences impacted their education and learning opportunities.

Learning Objectives. In the assessment of Task 1, the students prepared plots of understeer gradients similar to Figures 11 and 12 to measure the changes and compare with their comments. Students universally commented on how much more realistic the model from the high-end gaming experiment felt compared against the bicycle model in the low-end experiment. The ability to change the values of the vehicle parameters also proved to be a very instructive tool, as students quickly learned how a change in a vehicle parameter resulted in a change in vehicle performance, in what direction and in what magnitude.

In Task 2, students were tasked to drive around the racetrack shown in Figure 13 as fast as possible. The figure also plots the sum of vehicle paths for approximately 25 drivers, including off course excursions. The direction of travel is counterclockwise.

While the track is not complicated, the large number of paths off course in the one right-handed corner indicates that there was definitely a learning curve at work-almost every driver overshot that corner on their first lap. Within a handful of laps most students were driving proficiently, 


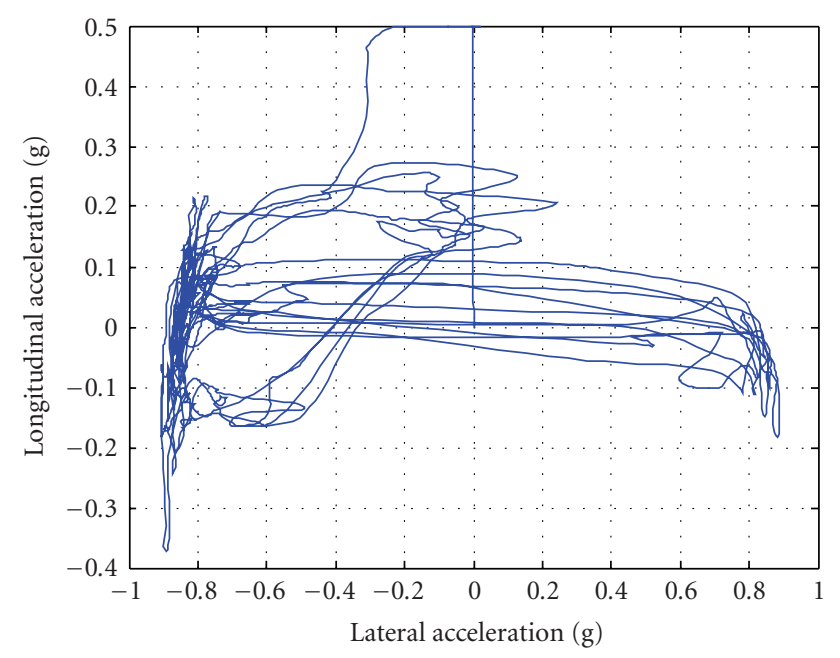

FIGURE 14: g-g diagram for a smooth driver over four laps. Note the repeatability.

although not necessarily expertly, on the course. With so many students being adept at video games the transition to the simulation in this kind of learning environment was faster than expected.

Many students learned about the vehicle instabilities at varying speeds abruptly when they entered the first turn too fast (top of Figure 13), braked too hard, and spun themselves out. They also experienced lateral force rolloff, the reduction in lateral force with large tractive, or braking forces. This was evident in the entrance to the straightaway as drivers who applied too much throttle found the rear of the vehicle difficult to control.

In Task 3 assessment, students created their own g-g and $\mathrm{CN}-\mathrm{AY}$ diagrams [39]. Figure 14 shows a g-g diagram for a smooth driver over four laps on the course. This plot of planar vehicle accelerations illustrates how much time the vehicle spends at the lateral acceleration limits for this vehicle (approx. $0.9 \mathrm{~g}$ ). Figure 15 presents a $\mathrm{CN}-\mathrm{AY}$ diagram for the same driver. This diagram presents yaw acceleration versus lateral acceleration, and a smooth driver will have very small values on the $y$-axis.

Figures 16 and 17 show similar figures for a driver who is much less smooth over the course of four laps. This data includes one spinout. Compared with the previous driver there is no distinct pattern in these plots. The first driver's data is more in line with what a professional proving ground driver or race driver would produce from in-car measurements.

Impact on Education. A more comprehensive survey was given at the end of the RVD2 class. The survey results shown in Table 2 reflect the mean of the responses of the 41 students who completed the course ( 2 students resigned the course). The items in Table 2 capture the responses that most aligned with the objectives of the gaming laboratory experience. The omitted items relate more to teaching methodology employed in the course. The questions were on a 5-point

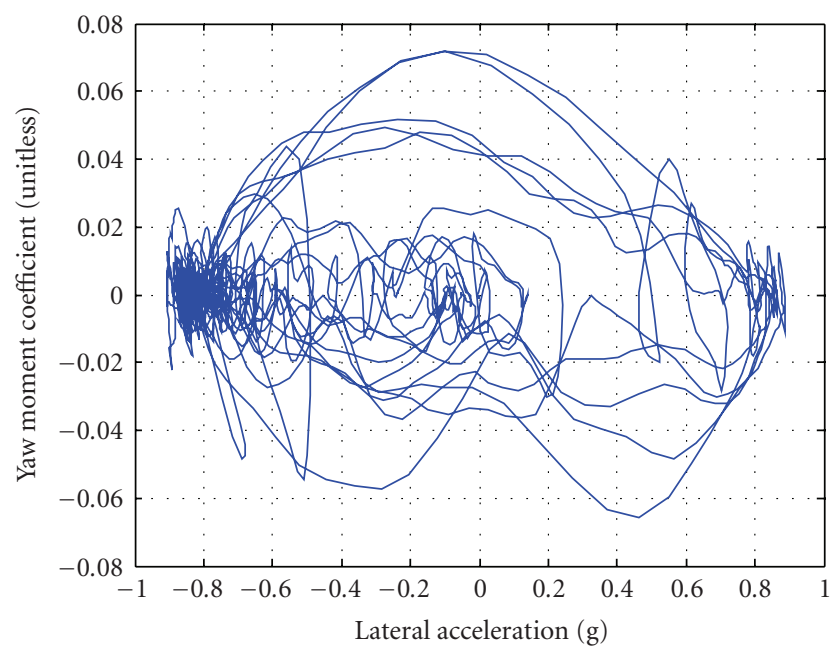

Figure 15: CN-AY diagram for a smooth driver. Note small yaw moment values.

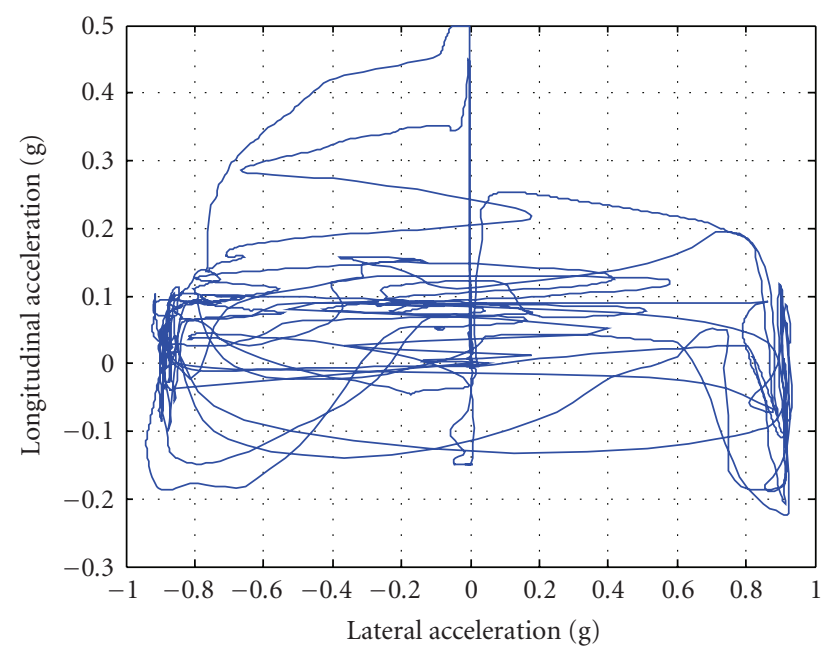

FIgURE 16: g-g diagram for a less-smooth driver.

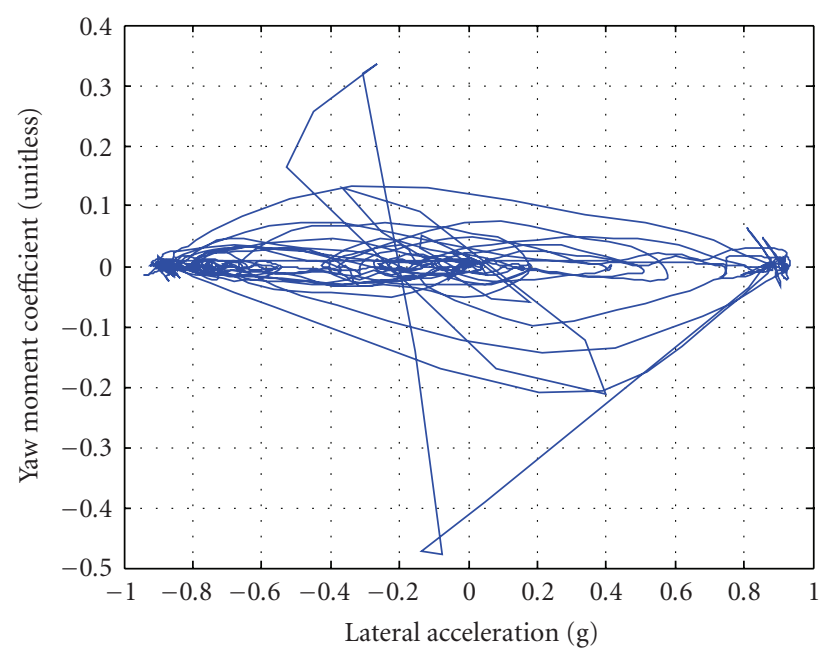

FIgURe 17: CN-AY for a less-smooth driver includes one spinout. 
TABLE 2: RVD ratings survey results.

\begin{tabular}{lcc}
\hline & RVD1 \& RVD2 have ... & $\begin{array}{c}\text { Other engineering courses } \\
\text { have ... }\end{array}$ \\
\hline Exposed me to genuine engineering problems** & 4.439 & 3.195 \\
Allowed for hands-on learning experiences** & 4.512 & 2.902 \\
Prepared me for the workplace** & 3.951 & 3.097 \\
Allowed me to use the types of technology and facilities that engineers use & 3.878 & 2.951 \\
in today's workforce** & 4.220 & 3.610 \\
Offered me a chance to identify and formulate engineering problems** & 4.537 & 3.293 \\
Provided engaging learning opportunities** & 3.854 & 3.049 \\
Made use of problems and situations similar to those that I expect to face & 3.829 & 3.073 \\
in the workplace** & 4.268 & 3.244 \\
Helped me be more familiar with what a practicing engineer does** & 4.732 \\
Given me opportunities to perform experiments in engineering** & 4.707 \\
Given me opportunities to analyze engineering data** & 4.463 \\
Given me opportunities to interpret engineering data** & 3.537 \\
Presented new ideas and material in a realistic context** & 3.463 \\
\hline
\end{tabular}
${ }^{* *} P<.001$.

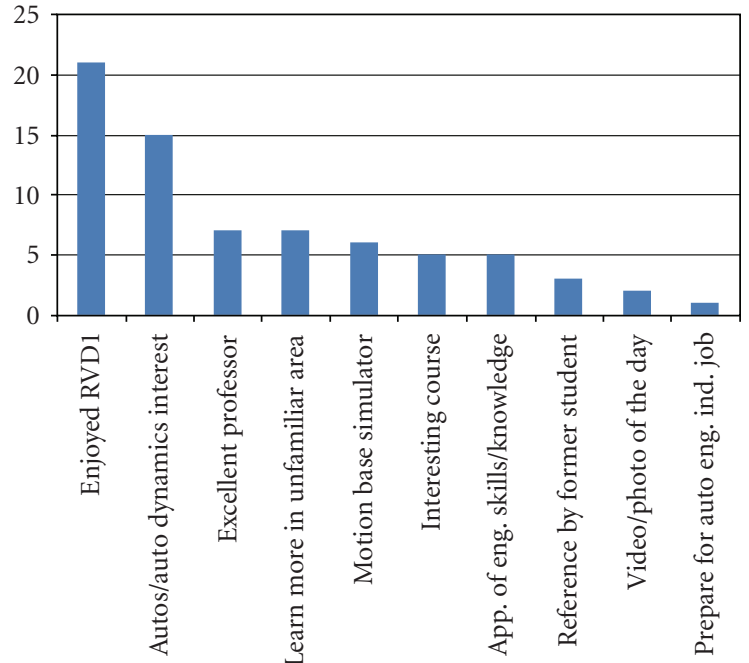

Figure 18: RVD2 responses to the question "Why did you take RVD2?”.

Likert scale with 1 representing strongly disagree and 5 representing strongly agree. An ANOVA was run for each item, and statistical significance between means, as denoted in the table, was found for all of the survey items. These responses provide evidence that students perceived the RVD2 course (and RVD1 course), including the laboratory gaming component to be of significant value in their engineering education.

In addition, the survey also included open-ended items, one of which asked them why they had enrolled in RVD2. All 41 students responded to this item, some with multiple responses. They are categorized and compiled in Figure 18. Note that the fifth most popular response was one that mentioned specifically the motion simulation gaming environment. The most popular responses mention their

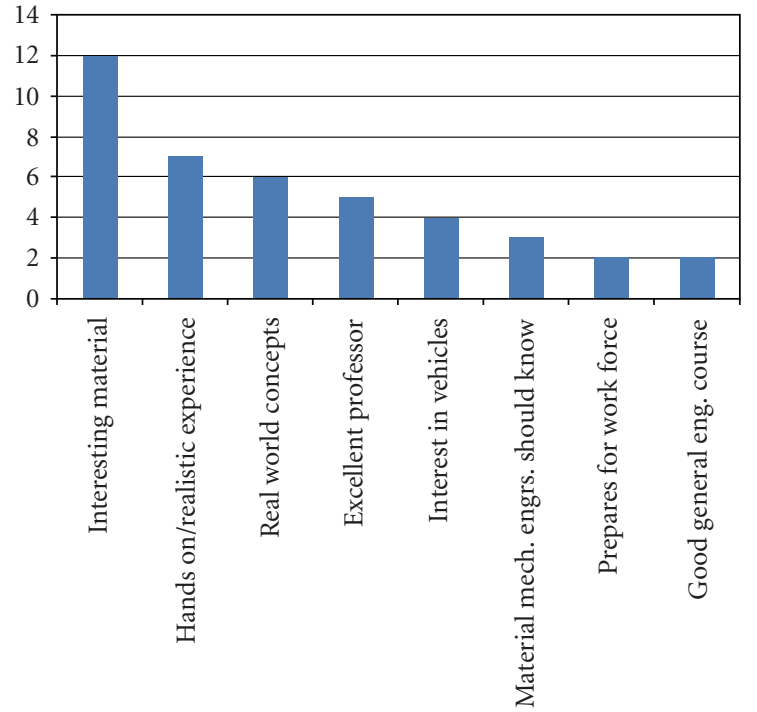

FIgUre 19: Reasons to take RVD1 and RVD2.

experiences in RVD1 which could certainly include the gaming experiences that were part of the class.

An additional item on the survey asked the RVD2 students if they would recommend either RVD1 or RVD2 to other students. All 41 RVD2 students responded affirmatively. Figure 19 displays the reasons that were given for this recommendation. Note that the second most popular response articulates the hand-on gaming experience in both classes.

Experiment Redesign. Section 6 addresses some overall insights and conclusions from the collective set of experiments. It also presents some ideas toward future redesigns of the experiments, based on the collected feedback. 


\section{General Insights and Conclusions}

This paper presents a method of using a simulation game to present students with an authentic vehicle testing scenario. The driving simulation environment is used to augment two standard road vehicle dynamics course offerings. In all, 73 students participated the low-end gaming tasks and 41 of these students continued with the second course and participated in the high-end gaming tasks. Based on the experimental results from performing these tasks, from in-laboratory observations (before, during, and after the experiments), and based on the student surveys (before and after the laboratory experiments), numerous conclusions can be drawn.

(i) The game scenarios were successful in attaining their primary goal-to serve as a forum for experiential, inquiry-based learning within an educational setting that had previously been instructed exclusively by way of traditional, lecture-based classroom approaches. Students would first see and experience the dynamics of a vehicle, hands-on, using the motion simulator, and this exposure was followed by traditional instruction (i.e., representative mathematical theory and governing dynamics equations) in the classroom setting.

(ii) The instructor noted significant differences between the students who engaged in the gaming experiments and those from previous nongaming offerings of the courses with respect to the learning objectives of each experiment. He noted substantial and identifiable progress in the students with respect to their comprehension of theoretical concepts and application of these concepts to practical vehicle design issues. In previous years a few in-class computer simulations with plots of output variables were used to illustrate different vehicle behaviors. With the use of the motion simulation experiment the connection between theory and reality was easier to make since the students had experienced the various vehicle behaviors. Interestingly, because of the realistic context that the experiments provided, the instructor also noted a pronounced familiarity with the technical vocabulary of the course after the experiments were conducted.

(iii) For each of the laboratory groups, the laboratory instructors could easily detect the progression of knowledge and lesson comprehension during the experiments. With the first driver, there would always be a considerable amount of apprehension and guesswork, as the student would serve as the first person to complete the exercise. Based on that student's successes and shortcomings, the second, and third drivers would conquer the exercises much more quickly and confidently, and generally speaking, improved driver performance in each session reflected this trend.

(iv) With 114 students in 19 groups across two semesters, almost 200 experimental setups were performed.
Using a physical vehicle and test track or road course, the setup time would have dominated the experimental process, limiting the students' ability to explore the impact changes in configuration have on vehicle dynamics.

(v) The results from the course surveys show that the course has a considerable impact on how students felt about their engineering education and their perceived experiences in their educational process. The use of experiential learning in the vehicle dynamics curriculum increased students' opinions of their opportunity to have hands on experiences, use modern engineering tools, and solve problems that were similar to what they expect to see in the workplace. This outcome shows that using simulation to provide authentic learning environments provides educators with a means of following the guidance provided by ABET and the National Survey of Student Engagement, with the ultimate goal of educating engineers that are better prepared for the workforce.

(vi) Further development and study will include more experiments aimed at using gaming environments to learn key technical concepts including fundamental vehicle dynamics, driver-vehicle interactions, and driver-to-driver interactions in networked simulations. The networking feature will allow multiple drivers to interact with one another within the same driving environment using both TCP and UDP internet protocols. In addition, future plans could include developing a computing toolkit to allow other researchers and educators interested in vehicle and motion simulation gaming applications to efficiently develop environments and experiments, similar to the more general serious game design and assessment toolkit in [45]. This toolkit could also be applied to a desktop version of driving simulation environments, allowing for greater dissemination and study.

\section{Acknowledgments}

The work described in this paper is supported in part by the National Science Foundation Course, Curriculum and Laboratory Improvement (CCLI) program (Grant DUE0633596) and the New York State Foundation for Science, Technology, and Innovation (NYSTAR).

\section{References}

[1] Sony Computer Entertainment, Gran Turismo, September 2008, http://us.playstation.com/granturismo/.

[2] Atari, Race Pro, September 2008, http://videogames.atari .com/racepro/.

[3] P. Wankat and F. Oreovicz, "Learning outside the classroom," ASEE Prism, vol. 10, no. 5, p. 32, 2001. 
[4] P. Wankat and F. Oreovicz, "An over-stuffed curriculum," ASEE Prism, vol. 11, no. 2, p. 40, 2001.

[5] P. Wankat and F. Oreovicz, "Getting out of your box," ASEE Prism, vol. 13, no. 3, p. 49, 2003.

[6] P. Wankat and F. Oreovicz, "Simulators to stimulate students," ASEE Prism, vol. 13, no. 5, p. 45, 2004.

[7] President's Information Technology Advisory Committee, "Using information technology to transform the way we learn," Tech. Rep., National Coordination Office for Information Technology Research and Development, Arlington, Va, USA, 2001.

[8] The Accreditation Board for Engineering and Technology, "Criteria for accrediting programs in engineering in the United States," Tech. Rep., Accreditation Board for Engineering and Technology, Baltimore, Md, USA, 2000.

[9] "National survey of student engagement: the college student report," Annual Report, Center for Postsecondary Research, Indiana University, Bloomington, Ind, USA, 2003.

[10] D. Dixon, "Manifest Technology, Making Sense of Digital Media Technology-Simulation-based Authoring for Serious Games," March 2005, http://www.manifest-tech .com/ce_games/sovoz_serious_games.htm\#References/.

[11] S. Lane, "Promoting Learning by Doing Through Simulations and Games," soVoz, Inc., White Paper, Princeton, NJ, USA, 2005.

[12] M. Prensky, Digital Game-Based Learning, McGraw-Hill, Boston, Mass, USA, 2001.

[13] V. Ruohomaki, "Viewpoints on learning and education with simulation games," in Simulation Games and Learning in Production Management, J. O. Riis, Ed., pp. 14-28, Springer, Berlin, Germany, 1995.

[14] M. Matijasevic, "A review of networked multi-user virtual environments," Tech. Rep. TR97-8-1, The Center for Advanced Computer Studies, Virtual Reality an Multimedia Laboratory, The University of Southwestern Louisiana, Lafayette, La, USA, 1997.

[15] C. Schoeneman, BZFlag, March 2008, http://bzflag.org/.

[16] Battlezone, Original game by Atari Inc., Consumer Division, 1312 Crossman Ave., P. O. Box 61657, Sunnyvale, Calif, USA 94086, 1980.

[17] B. J. Schachter, Ed., Computer Image Generation, John Wiley \& Sons, New York, NY, USA, 1983.

[18] W. Wright, "SimCity," March 2008, http://simcitysocieties .ea.com/index.php/.

[19] C. Sawyer, "Roller Coaster Tycoon," March 2008, http://www .atari.com/rollercoastertycoon/us/.

[20] J. P. Merlet, "Parallel manipulators-part I: theory, design, kinematics, dynamics and control," Tech. Rep. 646, INRIA, Cedex, France, 1987.

[21] D. Stewart, "A platform with six degrees of freedom," Proceedings of the Institution of Mechanical Engineers, vol. 180, no. 15, pp. 371-384, 1965.

[22] E. F. Fichter, "A stewart platform-based manipulator: general theory and practical construction," The International Journal of Robotics Research, vol. 5, no. 2, pp. 157-182, 1986.

[23] C. Aldrich, Learning by Doing: A Comprehensive Guide to Simulations, Computer Games, and Pedagogy in E-Learning and Other Educational Experiences, John Wiley \& Sons, San Francisco, Calif, USA, 2005.

[24] S. de Freitas, "Learning in immersive worlds: a review of game-based learning," Joint Information Systems Committee, December 2007, http://www.jisc.ac.uk/media/documents/ programmes/elearninginnovation/gamingreport_v3.pdf/.
[25] B. Stroustrup, The C++ Programming Language, AddisonWesley, Reading, Mass, USA, 1987.

[26] J. Postel, “User datagram protocol,” DARPA Network Working Group Report RFC 768, USC/Information Sciences Institute, Los Angeles, Calif, USA, 1980.

[27] Moog Systems Division, "Moog 6 DOF 2000E Motion System Interface Definition Manual," Doc. no. LSF-0446, East Aurora, NY, USA, 1999.

[28] "DirectInput C/C++ Reference," Microsoft Corporation, 2007, http://msdn.microsoft.com/en-us/library/bb219807(VS $.85) \cdot \operatorname{aspx} /$.

[29] J. Brooks, "Direct input 7 joystick class," Technical Article, CodeGuru, September 2008, http://www.developer.com/.

[30] R. Roman, "Non-linear optimal tilt coordination for washout algorithms," in Proceedings of the AIAA Modeling and Simulation Technologies Conference and Exhibit, Austin, Tex, USA, August 2003.

[31] M. A. Nahon and L. D. Reid, "Simulator motion-drive algorithms-A designer's perspective," AIAA Journal of Guidance, Control, and Dynamics, vol. 13, no. 2, pp. 356-362, 1990.

[32] R. J. Telban, W. Wu, and F. M. Cardullo, "Motion cueing algorithm development initial investigation and redesign of the algorithms," Tech. Rep. NASA/CR-2000-209863, National Aeronautics and Space Administration, Langley Research Center, Washington, DC, USA, 2000.

[33] M. Woo, J. Neider, T. Davis, and D. Shreiner, Open GL Programming Guide, Addison-Wesley, Reading, Mass, USA, 3rd edition, 2000.

[34] D. Burns and R. Osfield, "Open scene graph a: introduction, b: examples and applications," in Proceedings of the IEEE Virtual Reality Conference (VR '04), p. 265, Chicago, Ill, USA, March 2004.

[35] Delta3D, Naval Postgraduate School, MOVES Institute, September 2008, http://www.delta3d.org/.

[36] A. Geist, A. Beguelin, J. Dongerra, J. Weicheng, R. Mancheck, and V. Sunderam, PVM: Parallel Virtual Machine: A Users' Guide and Tutorial for Network Parallel Computing, The MIT Press, Cambridge, Mass, USA, 1994.

[37] R. Yadav, "Client/Server programming with TCP/IP sockets," Technical Article, DevMentor, September 2007, http://www.devmentor.org/.

[38] OpenAL 1.1 Specification and Reference, 2005, http:// www.openal.org/openal_webstf/specs/OpenAL11 Specification.pdf/.

[39] W. F. Milliken and D. L. Milliken, Race Car Vehicle Dynamics, SAE International, Warrendale, Pa, USA, 1995.

[40] SAE Vehicle Dynamics Standards Committee, "Steady-state directional control test procedures for passenger cars and light trucks," SAE Standard J266, SAE International, Warrendale, Pa, USA, 1996.

[41] P. van Valkenburg, Race Car Engineering and Mechanics, HP Trade, New York, NY, USA, 2004.

[42] W. Milliken and D. Milliken, Chassis Design: Principles and Analysis, SAE International, Warrendale, Pa, USA, 2002.

[43] Calspan, "Tire Research Facility (TIRF)," December 2008, http://www.calspan.com/pdfs/Tire_Research.pdf/.

[44] E. Kasprzak and D. Gentz, "The formula SAE tire test consortium - tire testing and data handling," SAE Paper 200601-3606, Society of Automotive Engineers, Warrendale, Pa, USA, 2006.

[45] R. J. Nadolski, H. G. K. Hummel, H. J. van den Brink, et al., "EMERGO: a methodology and toolkit for developing serious games in higher education," Simulation \& Gaming, vol. 39, no. 3, pp. 338-352, 2008. 

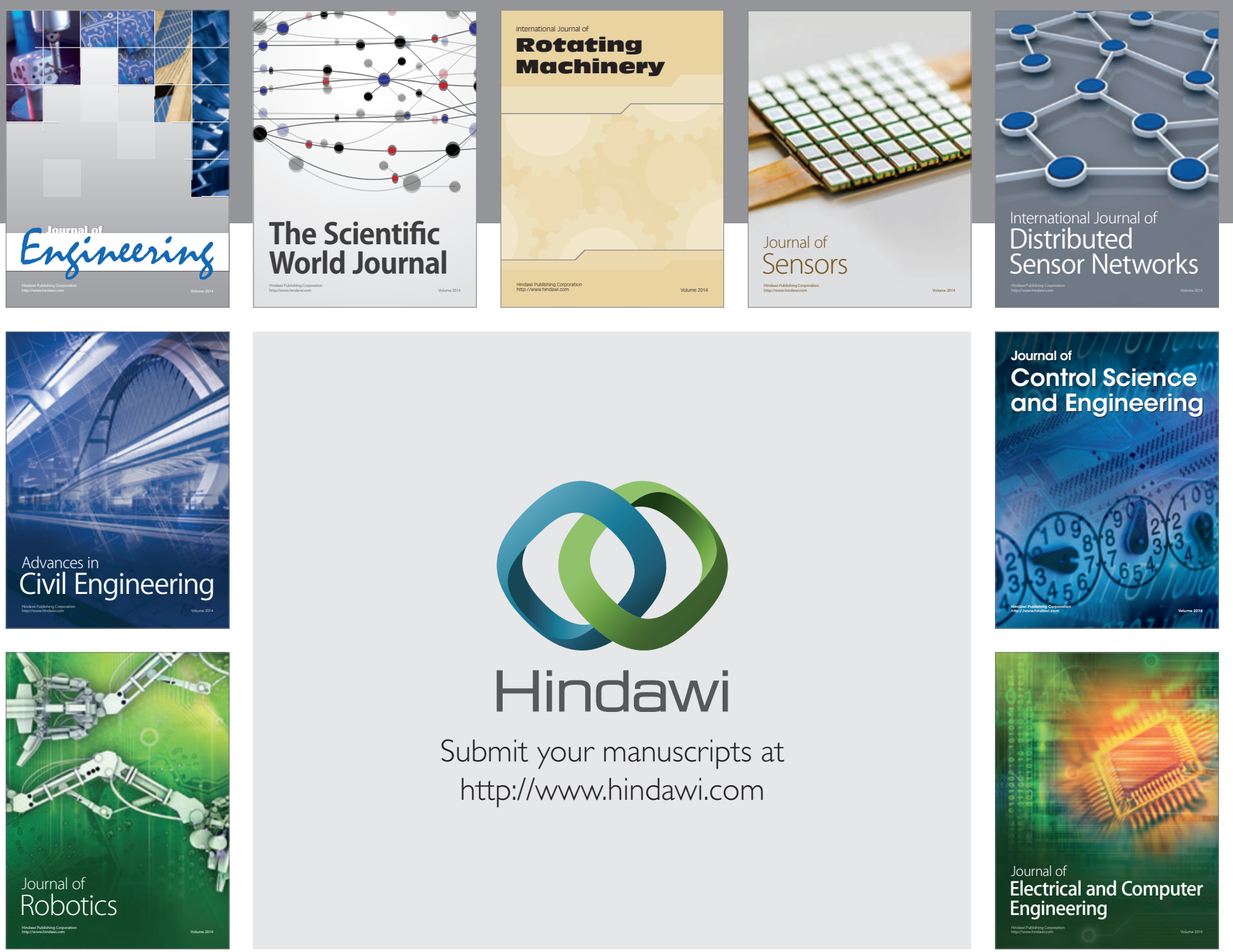

Submit your manuscripts at

http://www.hindawi.com
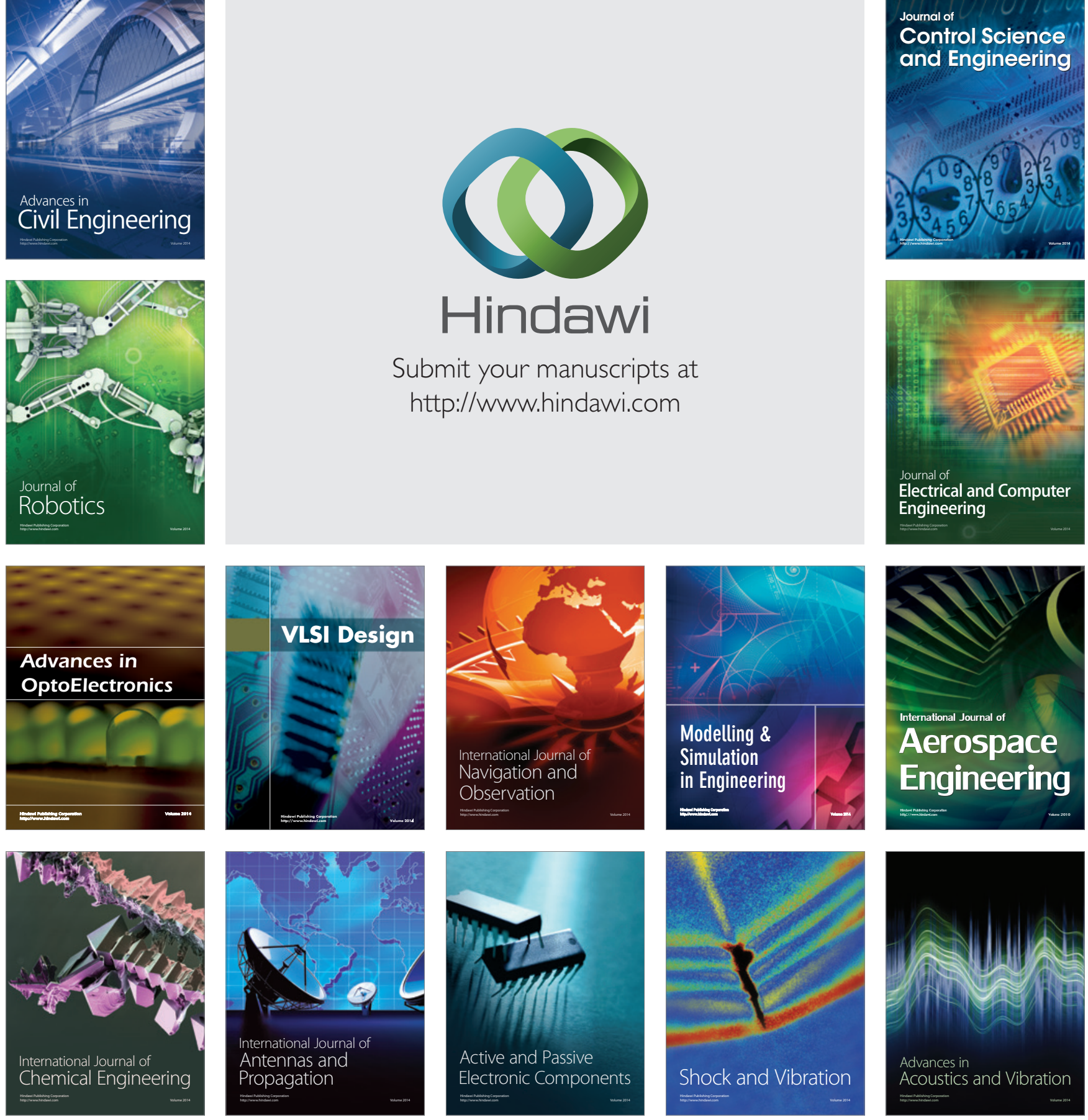